\title{
Synaptic Vesicular Glutamate Uptake: Modulation by a Synaptosomal Cytosolic Factor
}

\author{
* Anne T. Lobur, $¥$ Phillip E. Kish, and *†Tetsufumi Ueda \\ *Departments of Pharmacology and $\uparrow P$ sychiatry, and $\$$ Mental Health Research Institute, \\ The University of Michigan, Ann Arbor, Michigan, U.S.A.
}

\begin{abstract}
We have demonstrated previously that L-glutamate is taken up into isolated synaptic vesicles in an ATP-dependent manner, supporting the neurotransmitter role of this acidic amino acid. We now report that a nerve terminal cytosolic factor inhibits the ATP-dependent vesicular uptake of glutamate in a dose-dependent manner. This factor appears to be a protein with a molecular weight $>100,000$, as estimated by size exclusion chromatography, and is precipitated by ammonium sulfate ( $40 \%$ saturation). The inhibitory factor is inactivated by heating to $100^{\circ} \mathrm{C}$. Proteolytic digestion of the ammonium sulfate fraction by trypsin or chymotrypsin did not reduce, but rather increased slightly, the inhibition of glutamate uptake. Unlike the native factor, the digest re-
\end{abstract}

tained inhibitory activity after heating, suggesting that proteolytic digestion may generate active fragments. The inhibition of ATP-dependent vesicular glutamate uptake is not species-specific, as the factor obtained from both rat and bovine brains produced an equal degree of inhibition of glutamate uptake into vesicles of each species. These observations raise the possibility that vesicular uptake of glutamate may be regulated by an endogenous factor in vivo. Key Words: Glutamate uptake-Vesicles-Cytosolic factor. Lobur A. T. et al. Synaptic vesicular glutamate uptake: Modulation by a synaptosomal cytosolic factor. $J$. Neurochem. 54, 1614$1618(1990)$.
Glutamate is now widely accepted as the major excitatory neurotransmitter in the vertebrate CNS, as well as in the invertebrate neuromuscular junction (Watkins and Evans, 1981; Fonnum, 1984; Fagg et al., 1986; Cotman et al., 1987, 1989). Abnormalities in glutamatergic transmission have been implicated in a variety of neurological disorders, including epilepsy, ischemiainduced neuronal degeneration, Huntington's chorea, and Alzheimer's disease (Meldrum, 1985; Greenamyre, 1986; Olney et al., 1986; Robinson and Coyle, 1987; Rothman and Olney, 1987). We and others have provided evidence that glutamate is taken up into isolated synaptic vesicles in an ATP-dependent manner (Naito and Ueda, 1983, 1985; Maycox et al., 1988), further supporting the role of glutamate as a neurotransmitter. This vesicular uptake system is highly specific for glutamate and is markedly stimulated by physiologically relevant, low millimolar concentrations of chloride. Based on the high degree of substrate specificity and on other unique properties of the vesicular glutamate uptake system, it has been proposed that the fate of glutamate as a neurotransmitter is determined at the level of vesicular uptake (Ueda, 1986). The evidence for the vesicular uptake of glutamate is in accord with the immunocytochemical observation that glutamate is concentrated in certain nerve endings, which are distinct from $\gamma$-aminobutyric acid (GABA)-containing nerve terminals (Storm-Mathisen et al., 1983). Nicholls and Sihra (1986) have provided evidence that calciumdependent release of glutamate originates from a noncytoplasmic pool. Together, these lines of evidence support the idea that glutamate is released from synaptic vesicles. Also consistent with this idea are studies (Fischer-Bovenkerk et al., 1988) indicating that the ATP-dependent vesicular uptake system is present in cerebellar granule cells, which are considered to be glutamatergic, but not in GABAergic Purkinje neurons. Moreover, it has been demonstrated recently that the ATP-dependent vesicular glutamate uptake system develops with a time course that closely parallels that of synaptogenesis (Kish et al., 1989), which is compatible with the supposition that vesicular glutamate uptake plays an important role in synaptic function. In view of the potential importance of the vesicular glutamate
Received August 18, 1989; revised manuscript received September 26, 1989; accepted September 29, 1989.

Address correspondence and reprint requests to Dr. T. Ueda at
Mental Health Research Institute, The University of Michigan, 205 Washtenaw Place, Ann Arbor, MI 48109, U.S.A.

Abbreviation used: GABA, $\gamma$-aminobutyric acid. 
uptake system in synaptic transmission and normal brain function, we began to explore the possibility that vesicular glutamate uptake may be regulated. In this report, we provide evidence that the vesicular glutamate uptake system is regulated by a soluble proteinaceous substance. A preliminary account of this study has been reported previously (Lobur et al., 1988).

\section{MATERIALS AND METHODS}

\section{Materials}

L- $\left[2,3-{ }^{3} \mathrm{H}\right]$ Glutamic acid $(46 \mathrm{Ci} / \mathrm{mmol})$, L-glutamic acid, and DEAE Bio-Gel A (100-200 mesh) were purchased from Amersham, Sigma, and Bio-Rad, respectively.

\section{Preparation of crude synaptic vesicles and} synaptosomal cytosol

Synaptic vesicles were prepared from 30-day-old rat cerebrum using the method of Kish and Ueda (1989). The tissue was homogenized in 10 volumes of solution A containing $0.32 M$ sucrose, $0.5 \mathrm{~m} M$ calcium acetate, $1 \mathrm{~m} M$ magnesium acetate, and $1 \mathrm{mM} \mathrm{NaCO}$, and the homogenate was centrifuged at $12,100 \mathrm{~g}_{\max }(10,000 \mathrm{rpm}$, Sorvall SS-34 rotor). The pellet (a crude synaptosomal fraction) was resuspended in 20 volumes of ice-cold lysing solution $(6 \mathrm{~m} M$ Tris-maleate, pH 8.1) for $45 \mathrm{~min}$, and centrifuged at $43,500 g_{\max }(19,000$ $\mathrm{rpm}$, Sorvall SS-34 rotor) for $15 \mathrm{~min}$ to pellet synaptic and mitochondrial membranes. The supernatant was then centrifuged at $200,000 \mathrm{~g}_{\max }(41,000 \mathrm{rpm}$, Beckman Ti45 rotor) for $70 \mathrm{~min}$. The crude vesicle pellets were resuspended in solution B containing $0.32 \mathrm{M}$ sucrose, $1 \mathrm{~m} M$ dithiothreitol, and $1 \mathrm{mM} \mathrm{NaHCO}(0.5 \mu \mathrm{l} / \mathrm{mg}$ of original wet tissue $)$. The supernatant was collected and used as a crude synaptosomal cytosolic fraction. This cytosolic fraction contained the inhibitory factor. Bovine vesicles and synaptosomal cytosolic fractions were prepared in the same manner as described by Kish and Ueda (1989).

Protein was determined using the method of Lowry et al. (1951) with bovine serum albumin as the standard.

\section{Standard assay for vesicular glutamate uptake}

The uptake of glutamate into crude vesicles was assayed as previously described (Naito and Ueda, 1983, 1985) with slight modifications. The standard uptake medium (final volume, $100 \mu \mathrm{l}$ ) contained $0.25 \mathrm{M}$ sucrose, $10 \mathrm{mM} \mathrm{MgSO}_{4}, 5$ $\mathrm{m} M$ HEPES (pH 7.4), $20 \mathrm{~m} M$ aspartate, $4 \mathrm{mM} \mathrm{KCl}, 50 \mu \mathrm{g}$ of rat crude synaptic vesicles, 0 or $7 \mathrm{mM}$ ATP (neutralized to $\mathrm{pH} 7.4$ with Tris base), unlabeled glutamate, and $\left[{ }^{3} \mathrm{H}\right.$ ]glutamate $(500 \mu \mathrm{M}$; specific activity, $0.04 \mathrm{Ci} / \mathrm{mmol}$ ). Uptake was initiated by the addition of a mixture $(20 \mu \mathrm{l})$ containing ATP and labeled and unlabeled glutamate. The mixture was incubated at $30^{\circ} \mathrm{C}$ for $5 \mathrm{~min}$, followed by the addition of $2 \mathrm{ml}$ of ice-cold $0.15 \mathrm{M} \mathrm{KCl}$ and immediate filtration through Millipore HAWP filters $(25 \mathrm{~mm}, 0.45 \mu \mathrm{m})$. The test tubes were washed three more times and the filters an additional three times with ice-zold KCl. The radioactivity retained on the filters was quantified using a liquid scintillation spectrophotometer. Glutamate uptake activity in the absence of ATP was subtracted from the activity in the presence of ATP. Control uptake activity was defined as the ATPdependent uptake activity determined in the absence of the inhibitory factor. ATP-dependent glutamate uptake and inhibitory activity also could be demonstrated using $125 \mathrm{mM}$ potassium isethionate, or $63 \mathrm{mM}$ potassium tartrate and 61 $\mathrm{m} M$ sucrose, in place of $0.25 M$ sucrose.

\section{Assay of the inhibitory factor}

Vesicular glutamate uptake was measured in the presence and absence of the factor as described above. One unit of the inhibitory factor is defined as the amount of factor required to inhibit ATP-dependent uptake by $50 \%$. The inhibitory factor had little effect on the glutamate uptake observed in the absence of ATP.

\section{Ammonium sulfate precipitation of the inhibitory factor}

The presence of a soluble inhibitory factor was first detected in the crude synaptosomal cytosol. Solid ammonium sulfate was added to a constantly stirred synaptosomal cytosol fraction, to $40 \%$ saturation, at $4^{\circ} \mathrm{C}$. Addition took $25 \mathrm{~min}$. The solution was allowed to stand on ice for an additional 30 min, stirred briefly, and centrifuged at $20,000 \mathrm{~g}_{\max }$ for 20 min. The pellet was resuspended in a minimal volume of 10 $\mathrm{m} M$ Tris-maleate $(\mathrm{pH} 7.0)$ and dialyzed overnight against at least 1,000 volumes of $10 \mathrm{~m} M$ Tris-maleate (pH 7.0). Most of the inhibitory activity $(82 \%)$ was fractionated in the precipitate from $40 \%$ saturation with ammonium sulfate. This material was used in all experiments.

\section{RESULTS}

\section{Effect of various concentrations of the inhibitory factor}

The partially purified factor inhibited ATP-dependent glutamate uptake in a concentration-dependent manner (Fig. 1). The ammonium sulfate fractionation resulted in an approximate twofold increase in specific activity. Complete inhibition has never been observed. It is possible that the residual activity (about 20\%) represents a subtype of the vesicular glutamate uptake system that is insensitive to the endogenous inhibitory factor.

\section{Characterization of the inhibitory factor}

Charge, size, and thermal stability. The ammonium sulfate fractionate was passed over a DEAE Bio-Gel A

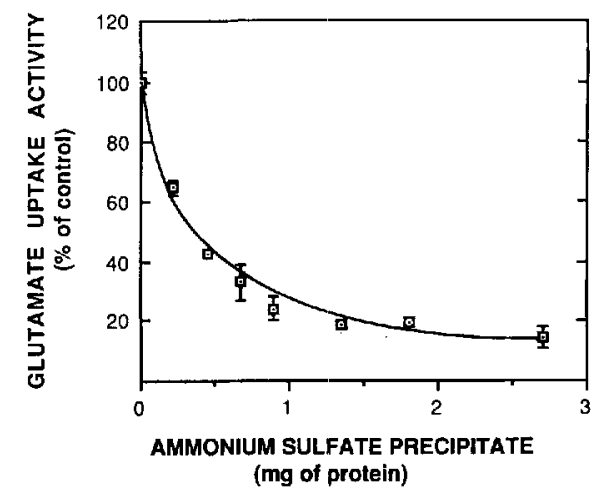

FIG. 1. Effect of various concentrations of the inhibitory factor on vesicular glutamate uptake. Vesicular glutamate uptake was assayed, under standard conditions, with the addition of various amounts of the $40 \%$-saturated ammonium sulfate precipitate $(0.23$ $2.7 \mathrm{mg}$ of protein). These uptake values are expressed as percentage of ATP-dependent uptake activity observed in the absence of ammonium sulfate precipitate (control). The glutamate uptake in the control was $217.8 \pm 3.5 \mathrm{pmol} / 5 \mathrm{~min} / 50 \mu \mathrm{g}$ of protein. 
column. Part of the inhibitory activity was detected in the flow-through material, which was not retained on the column, and a portion of the inhibitory activity was eluted with $0.13-0.26 \mathrm{M} \mathrm{KCl}$ (data not shown). This suggests that there may be two inhibitory factors, one basic and one acidic. When the acidic inhibitory factor was subjected to gel filtration on a Bio-Gel P100 column, it was found in the void volume fractions, suggesting a molecular weight $>100,000$ (data not shown). When the ammonium sulfate was subjected to heat treatment, most of the inhibitory activity was lost within the first minute of heating to $100^{\circ} \mathrm{C}$. In contrast, the inhibitory activity was stable at room temperature for at least $4 \mathrm{~h}$ (data not shown).

Effects of treatment with proteolytic enzymes. The effects of trypsin and chymotrypsin treatments on the inhibitory activity are shown in Table 1 . Neither enzyme was able to abolish the inhibitory activity. In fact, trypsin treatment appears to result in a slight increase in the inhibitory activity (Fig. 2).

The data in Table 2 demonstrate the thermal stability of the chymotrypsin digest of the inhibitory factor. In contrast with the native inhibitory factor, the chymotryptic digest is resistant to inactivation by heat $\left(100^{\circ} \mathrm{C}\right)$. The control sample, which was not treated with chymotrypsin, demonstrated approximately $80 \%$ inhibitory activity. Inactivated chymotrypsin alone had no effect on glutamate uptake. The chymotrypsintreated factor had inhibitory activity comparable to that of the untreated factor. It is interesting that upon treatment at $100^{\circ} \mathrm{C}$, the chymotrypsin-treated sample retained its original inhibitory activity, whereas the untreated sample lost the activity.

Species and tissue specificity. In experiments not presented here, the soluble inhibitory factor prepared

TABLE 1. Effect of treatment with trypsin or chymotrypsin on the inhibitory factor

\begin{tabular}{lc}
\hline \multicolumn{1}{c}{ Additions } & $\begin{array}{c}\text { Glutamate uptake } \\
\text { (\% of control) }\end{array}$ \\
\hline None (control) & 100 \\
AS precipitate & $37 \pm 2$ \\
Trypsin & $97 \pm 2$ \\
Trypsin-treated AS precipitate & $20 \pm 1$ \\
Chymotrypsin & $90 \pm 4$ \\
Chymotrypsin-treated AS precipitate & $30 \pm 0.2$ \\
\hline
\end{tabular}

The $40 \%$-saturated ammonium sulfate precipitate (AS precipitate, $4.5 \mathrm{mg}$ of protein) was incubated at $30^{\circ} \mathrm{C}$ for $5 \mathrm{~min}$ in the presence and absence of trypsin or chymotrypsin $(0.1 \mathrm{mg} / \mathrm{ml})$, in a final volume of $200 \mu$ l containing $7.5 \mathrm{~m} M$ Tris-maleate ( $\mathrm{pH} 7.0$ ). Trypsin or chymotrypsin alone also was subjected to the same incubation conditions. After incubations, Bowman-Birk trypsin-chymotrypsin inhibitor was added to a final concentration of $0.1 \mathrm{mg} / \mathrm{ml}$. Aliquots $(30 \mu \mathrm{l})$ of sample from each reaction mixture were assayed for the ability to inhibit vesicular glutamate uptake. These values are expressed as percentage of control uptake activity $(220.7 \pm 11.6 \mathrm{pmol} / 5 \mathrm{~min} / 50$ $\mu \mathrm{g}$ of protein). In experiments not shown here, the trypsin-chymotrypsin inhibitor alone was shown to have no significant effect on glutamate uptake.

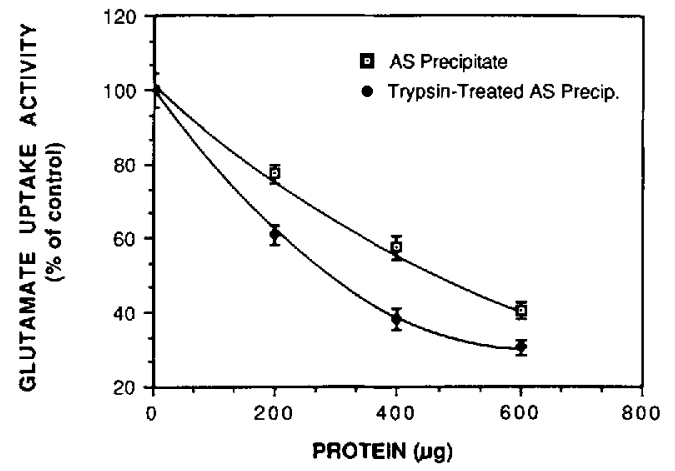

FIG. 2. Effect of trypsin treatment on inhibitory activity present in ammonium sulfate (AS) precipitate. The ammonium sulfate precipitate $(10.5 \mathrm{mg}$ of protein) was incubated with trypsin $(0.1 \mathrm{mg} / \mathrm{ml})$, as described in the footnote to Table 2, in a final volume of 0.35 $\mathrm{ml}$. The tryptic digestion was stopped with the addition of BowmanBirk trypsin-chymotrypsin inhibitor $(0.1 \mathrm{mg} / \mathrm{ml})$. Various aliquots of the digested material $(\$)$ and the undigested inhibitory factor $(\nabla)$ were assayed for their ability to inhibit vesicular glutamate uptake. Control glutamate uptake was $246.6 \pm 5.3 \mathrm{pmol} / 5 \mathrm{~min} / 50 \mu \mathrm{g}$ of protein.

from the rat brain exhibited a similar inhibitory activity in bovine synaptic vesicle preparations. Moreover, the inhibitory factor was shown to be present not only in the rat brain but also in the bovine brain.

A fraction comparable to the crude synaptosomal cytosol was prepared from rat "nonnervous" tissue, such as liver, kidney, and lung, as well as from brain, and subjected to ammonium sulfate fractionation. Each ammonium sulfate fractionate was then tested for the ability to inhibit vesicular glutamate uptake. Of the tissues tested, the inhibitory activity was detected in only brain tissue (data not shown). Within the brain, the inhibitory activity varied by region. The sample derived from the cerebral cortex exhibited $70 \%$ inhibition of the vesicular glutamate uptake, whereas

TABLE 2. Effect of boiling on the chymotrypsin-treated inhibitory factor

\begin{tabular}{lc}
\hline \multicolumn{1}{c}{ Additions } & $\begin{array}{c}\text { Glutamate uptake } \\
\text { (\% of control) }\end{array}$ \\
\hline None (control) & 100 \\
AS precipitate & $23 \pm 3$ \\
Chymotrypsin & $99 \pm 2$ \\
Chymotrypsin-treated AS precipitate & $22 \pm 1$ \\
AS precipitate, boiled & $77 \pm 0.8$ \\
Chymotrypsin-treated AS precipitate, boiled & $\mathbf{4 3} \pm 5$ \\
\hline
\end{tabular}

The $40 \%$-saturated ammonium sulfate precipitate (AS precipitate, $4.5 \mathrm{mg}$ of protein) was incubated at $30^{\circ} \mathrm{C}$ for $5 \mathrm{~min}$ in the presence or absence of $0.1 \mathrm{mg} / \mathrm{ml}$ chymotrypsin, in a final volume of $200 \mu \mathrm{l}$. Chymotrypsin alone or the precipitate alone also was subjected to the same incubation conditions. After incubation, chymotrypsin inhibitor was added to a final concentration of $0.1 \mathrm{mg} / \mathrm{ml}$. The chymotrypsin-treated, as well as the nontreated, precipitates were then heated to $100^{\circ} \mathrm{C}$ for $2 \mathrm{~min}$. Aliquots $(30 \mu \mathrm{l})$ of each sample were assayed for the ability to inhibit vesicular glutamate uptake. Control glutamate uptake was $230.5 \pm 14.6 \mathrm{pmol} / 5 \mathrm{~min} / 50 \mu \mathrm{g}$ of protein. 
equivalent samples prepared from the hippocampus, caudate nucleus, cerebellum, and brainstem showed about $40 \%$ inhibition (Fig. 3).

\section{DISCUSSION}

In this study, we have provided evidence for the existence of an endogenous inhibitory factor for vesicular glutamate uptake. The principal inhibitory factor is precipitated by ammonium sulfate ( $40 \%$ saturation), and appears to be an acidic substance with a molecular weight $>100,000$. Furthermore, the inhibitory factor is stable at room temperature, but labile at $100^{\circ} \mathrm{C}$, and is resistant to treatment with trypsin and chymotrypsin.

It is interesting that, after chymotryptic treatment, inhibitory activity survived heating to $100^{\circ} \mathrm{C}$, suggesting that chymotryptic treatment yielded fragments of the inhibitory factor that were no longer inactivated at $100^{\circ} \mathrm{C}$. These observations, together with the observation that the native inhibitory factor is excluded from Bio-Gel P-100, support the view that the factor is a proteinaceous substance that is cleaved to an active, heat-stable fragment by the proteolytic enzyme.

The tissue distribution studies indicate that the inhibitory factor is present predominantly in the brain, and, within the brain, occurs in various regions, including the cerebral cortex, hippocampus, caudate nucleus, and cerebellum, all of which are known to be rich in glutamatergic synapses (Greenamyre et al., 1984; Cotman et al., 1987). The factor is present not only in the rat brain but also in the bovine brain, and is capable of inhibiting glutamate uptake into both rat and bovine synaptic vesicles. These results suggest that a similar, if not identical, proteinaceous, inhibitory substance occurs in the brains of other species, and raise the possibility that such an endogenous factor

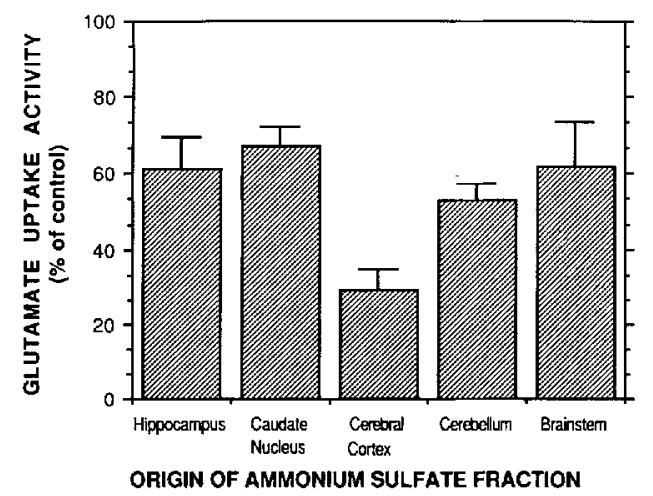

FIG. 3. Regional distribution of the inhibitory factor in rat brain. Ammonium sulfate ( $40 \%$ saturation) precipitates were prepared identically from synaptosomal cytosol from rat hippocampus, caudate nucleus, cerebral cortex, cerebellum, and brainstem. Aliquots containing equal amounts of protein $(0.25 \mathrm{mg})$ from each region were assayed for their ability to inhibit vesicular glutamate uptake. The data shown represent the mean \pm SD of two preparations. Control glutamate uptake was $214.4 \pm 8.7 \mathrm{pmol} / 5 \mathrm{~min} / 50 \mu \mathrm{g}$ of protein. could be involved in modulating the accumulation of glutamate into synaptic vesicles in vivo.

The mechanism by which the inhibitory factor achieves its effect is not understood at present. At least six possible mechanisms can be considered. First, the possibility that the inhibitory factor could be simply enzymatically degrading the glutamate uptake system is unlikely, as none of the protease inhibitors tested were able to diminish the inhibitory effect at concentrations known to inhibit proteolysis; these included soybean trypsin inhibitor $(100 \mu \mathrm{g} / \mu \mathrm{l})$, EGTA $(1 \mathrm{~m} M)$, phenylmethanesulfonyl fluoride $(100 \mu M)$, diisopropyl fluorophosphate $(1 \mathrm{~m} M)$, and leupeptin $(50 \mu M)$ (data not shown). Second, the factor could be an ATPase, which may substantially reduce ATP levels and thereby lead to an apparent inhibition. This possibility is also unlikely, as treatment of the crude synaptosomal cytosol at $60^{\circ} \mathrm{C}$ for 5 min totally abolished ATPase activity in the synaptosomal cytosol, but left approximately half the inhibitory activity intact. Treatment of the crude cytosol at $50^{\circ} \mathrm{C}$ for $5 \mathrm{~min}$ abolished more than half the ATPase activity, with $15 \%$ reduction in the inhibitory activity (data not shown). Moreover, the inhibitory activity of the factor was not abolished by increasing the concentration of ATP to $20 \mathrm{~m} M$. Third, the factor could be inhibiting ATP hydrolysis by the proton-pump ATPase in the vesicle membrane. This possibility also is unlikely because the factor did not affect the Mg-ATPase activity associated with the synaptic vesicles. Fourth, the factor could block the generation of membrane potential by interfering with proton translocation. Fifth, the factor could diminish glutamate uptake by blocking the chloride-induced stimulation. This possibility is unlikely, as the factor inhibited ATP-dependent uptake even in the absence of chloride (data not shown). Finally, the factor could inhibit glutamate uptake by binding to the putative glutamate translocator, distinct from the proton-pump ATPase. Thus, further studies are required to better understand the mechanism of action of the inhibitory factor.

It is well known that catecholamine uptake into storage vesicles is inhibited by reserpine, which results in reduction of adrenergic transmission (Weiner, 1970; Rand and Jurevics, 1977). Recently, regulation of transmitter uptake into synaptic vesicles derived from Torpedo electric organ has been described by Parsons et al. (1987). Although substances exist that affect the vesicular storage of transmitters, this is, to the best of our knowledge, the first report of an endogenous regulatory factor.

Regulation of glutamatergic synaptic transmission at the site of the postsynaptic receptors has been extensively studied, especially with respect to the $N$ methyl-D-aspartate receptor complex (Ascher and Nowak, 1987; Cotman and Iversen, 1987; Kemp et al., 1987; Watkins and Olverman, 1987). In contrast with the postsynaptic modulation of glutamate transmission, relatively little is known about the regulation of 
presynaptic vesicular glutamate. It has been observed that vesicular glutamate uptake is stimulated by low concentrations of chloride and inhibited by high concentrations (Naito and Ueda, 1985). Shank and Campbell (1984) have shown that glutamate and glutamine affect the uptake of $\alpha$-ketoglutarate, one of the proposed precursors of glutamate, into synaptosomes and astrogliasomes. This suggests that these amino acids may regulate the metabolic pool, and possibly the neurotransmitter pool, of glutamate. However, it remains to be seen whether the increase in glutamate concentration in the synaptic cleft upon evoked release indeed leads to a significant change in the neurotransmitter pool of glutamate, although it could regulate its metabolic pool. On the other hand, direct inhibition of the active transport system in the synaptic vesicle by an endogenous substance, such as the protein factor studied here or chloride ions, could represent a more effective means of modulating the transmitter pool of glutamate. Thus, the endogenous proteinaceous factor may serve a function in the regulation of the transmitter pool of glutamate. If the net content of glutamate accumulated into the synaptic vesicle is regulated, this regulation could result in an alteration in the level of glutamate released into the synapse upon depolarization, and thereby could modulate glutamate transmission. In extreme cases, breakdown of such a modulatory system could lead to derangements in glutamatergic transmission.

Acknowledgment: This work was supported by grants from the National Science Foundation (BNS 8509679) and the National Institutes of Health (NS 26884).

\section{REFERENCES}

Ascher P. and Nowak L. (1987) Electrophysiological studies of NMDA receptors. Trends Neurosci. 10, 284-288.

Cotman C. W. and Iversen L. L. (1987) Excitatory amino acids in the brain-focus on the NMDA receptors. Trends Neurosci. 10, 263-264.

Cotman C. W., Monahan D. T., Ottersen O. P., and Storm-Mathisen J. (1987) Anatomical organization of excitatory amino acid receptors and their pathways. Trends Neurosci. 10, 273-279.

Cotman C. W., Bridges R. J., Taube J. S., Clark A. S., Geddes J. W., and Monaghan D. T. (1989) The role of the NMDA receptor in central nervous system plasticity and pathology. J. NIH Res. $1,65-74$.

Fagg G. E., Foster A. C., and Ganong A. H. (1986) Excitatory amino acid synaptic mechanisms and neurological function. Trends Pharmacol. Sci. 7, 357-363.

Fischer-Bovenkerk C., Kish P. E., and Ueda T. (1988) ATP-dependent glutamate uptake into synaptic vesicles from cerebellar mutant mice. J. Neurochem. 51, 1054-1059.

Fonnum F. (1984) Glutamate: a ncurotransmitter in mammalian brain. J. Neurochem. 42, 1-11.
Greenamyre J. T. (1986) The role of glutamate in neurotransmission and in neurologic disease. Arch. Neurol. 43, 1058-1063.

Greenamyre J. T., Young A. B., and Penney J. B. (1984) Quantitative autoradiographic distribution of $\mathrm{L}-\left[\mathrm{H}^{3}\right]$ glutamate-binding sites in rat central nervous system. $J$. Neurosci. 4, 2133-2144.

Kemp J. A., Foster A. C., and Wong E. H. F. (1987) Non-competitive antagonists of excitatory amino acid receptors. Trends Neurosci. 10, 294-298.

Kish P. E. and Ueda T. (1989) Glutamate accumulation into synaptic vesicles, in Methods in Enzymology, Biomembranes, Part $U$ : Biological Transport Vol. 174, Cellular and Subcellular Transport: Eukaryotic (Non-Epithelial) Cells (Fleischer S. and Fleischer B., eds), pp. 9-25.

Kish P. E., Kim S. Y., and Ueda T. (1989) Ontogeny of glutamate accumulating activity in rat brain synaptic vesicles. Neurosci. Lett. 97, 185-190.

Lobur A. T., Kish P. E., and Ueda T. (1988) Evidence for a synaptosomal cytosolic factor modulating vesicular glutamate uptake. Soc: Neurosci. Abstr. 14, 275.18.

Lowry O. H., Rosebrough N. J., Farr A. L., and Randall R. J. (1951) Protein measurement with Folin phenol reagent. J. Biol. Chem. 193, 265-275.

Maycox P. R., Deckwerth T., Hell J. W., and Jahn R. (1988) Glutamate uptake by brain synaptic vesicles. J. Biol. Chem. 263, 15423-15428.

Meldrum B. (1985) Possible therapeutic applications of antagonists of excitatory amino acid neurotransmitters. Clin. Sci. 68, 113122.

Naito S. and Ueda T. (1983) Adenosine triphosphate-dependent uptake of glutamate into Protein I-associated synaptic vesicles. $J$. Biol. Chem. 258, 696-699.

Naito S. and Ueda T. (1985) Characterization of glutamate uptake into synaptic vesicles. $J$. Neurochem. 44, 99-109.

Nicholls D. G. and Sihra T. (1986) Synaptosomes possess an exocytotic pool of glutamate. Nature 321, 772-773.

Olney J. W., Collins R. C., and Sloviter R. S. (1986) Excitotoxic mechanism of epileptic brain damage. Adv. Neurol. 44, 857877.

Parsons S. M., Bahr B. A., Gracz L. M., Kaufman R., Kornreich W. D., Nilsson L., and Rogers G. A. (1987) Acetylcholine transport: fundamental properties and effects of pharmacologic agents. Ann. NY Acad. Sci. 493, 220-233.

Rand M. J. and Jurevics H. (1977) The pharmacology of raulwolfia alkaloids. Handb. Exp. Pharmacol. 39, 77-99.

Robinson M. B. and Coyle J. T. (1987) Glutamate and related acidic excitatory neurotransmitters: from basic science to clinical application. FASEB J. 1, 446-455.

Rothman S. M. and Olney J. W. (1987) Excitotoxicity and the NMDA receptor. Trends Neurosci. 10, 299-302.

Shank R. P. and Campbell G. LeM. (1984) Glutamine, glutamate, and other possible regulators of $\alpha$-ketoglutarate and malate uptake by synaptic terminals. $J$. Neurochem. 42, 1162-1169.

Storm-Mathisen J., Leknes A. K., Bore A. T., Vaaland J. L., Edminson P., Haug F.-M. S., and Ottersen O. P. (1983) First visualization of glutamate and GABA in neurons by immunocytochemistry. Nature 301, 517-520.

Ueda T. (1986) Glutamate transport in the synaptic vesicle, in $E x$ citatory Amino Acids (Roberts P. J., Storm-Mathisen J., and Bradford H. F., eds), pp. 173-195. Macmillan Press, London.

Watkins J. C. and Evans R. H. (1981) Excitatory amino acid transmitters. Annu. Rev. Pharmacol. Toxicol. 21, 165-204.

Watkins J. C. and Olverman H. J. (1987) Agonists and antagonists for excitatory amino acid receptors. Trends Neurosci. 10, 265272.

Weiner N. (1970) Regulation of norepinephrine biosynthesis. Annu. Rev. Pharmacol. 75 (Suppl.), 87-94. 